\title{
A Concepção de Violência Segundo Atores do Cotidiano de Uma Escola Particular - Uma Análise Psicológica
}

\author{
The violence conception according to \\ the daily performers of a private school: \\ A psychological analysis
}
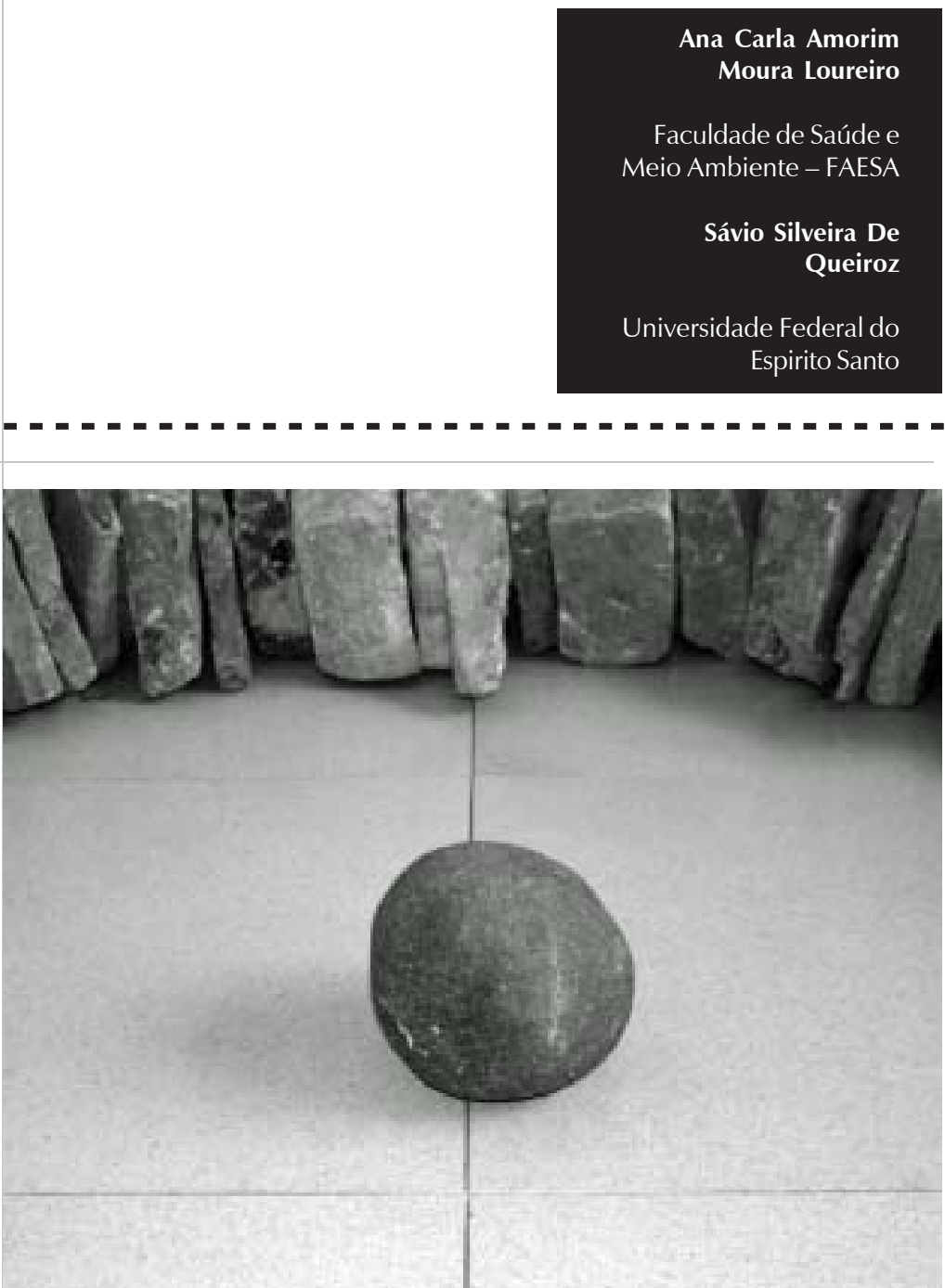


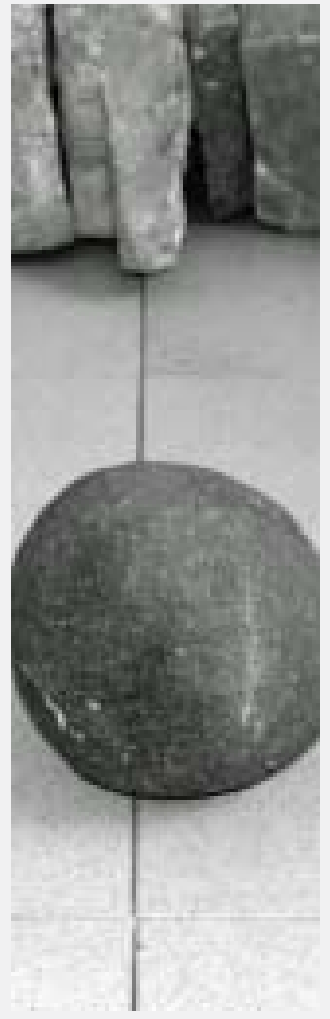

Resumo: O objetivo desta pesquisa foi verificar as concepções de violência escolar da equipe pedagógica, dos auxiliares de disciplina e de um grupo de estudantes de uma escola particular na Grande Vitória e analisar como lidam com a violência nesse espaço. A maioria dos entrevistados vê a violência na escola sob dois aspectos: o físico e o verbal. As causas da violência na escola foram relacionadas primeiramente à família desestruturada e ao ambiente em que o aluno ou a escola está inserido, o que indica uma visão pouco crítica das dinâmicas tecidas dentro da escola.

Palavras-chave: violência na escola, escola particular, autonomia moral.

\begin{abstract}
The objective of this work is to check the concepts of school violence among the members of a private school, in Vitória, and to analyze how they deal with violence. The majority of them take into account two aspects of school violence: the physical and the verbally expressed ones. The family which does not follow socially-acceptable parameters has been pointed out as the main cause of school violence; second, comes the enviroment in which the student lives or where the school is located, which shows the little importance attached to activities developed within the school building.
\end{abstract}

Key words: school violence, private school, moral authonomy.

O tema violência na escola tem sido, ultimamente, muito destacado nos meios de comunicação. Casos de tráfico e consumo de drogas dentro da escola, ameaças aos professores, agressões verbais, depredação do prédio escolar, brigas entre alunos e porte de armas têm sido constantemente noticiados como uma dura realidade das escolas brasileiras. No entanto, as escolas que geralmente são consideradas "portadoras" dessas dificuldades são as da rede pública de ensino. Poucas pesquisas contemplam as escolas particulares, principalmente quando o tema em tela é a violência.

Partimos da premissa que a violência pode emergir em todos os ambientes em que o conflito não é negociado e onde há intolerância ao diferente. Com isso, tanto a escola pública quanto a particular são possíveis geradoras de violência, apesar de apresentarem realidades distintas, principalmente no que concerne à estrutura material da escola e à classe social de sua clientela.

O fato de o ensino privado possuir, geralmente, uma estrutura física melhor e apresentar um quadro de professores com uma remuneração mais elevada que os da rede pública não significa que o modo como a aprendizagem é encaminhada em seu espaço esteja voltado para a construção da autonomia ${ }^{1}$ dos alunos. O autoritarismo, as ameaças, a desqualificação do aluno podem também fazer parte do cotidiano das escolas particulares. As normas que regem a escola e o funcionamento das classes podem ser extremamente severas e não negociadas com os outros participantes da dinâmica escolar. Com isso, as rebeldias podem emergir como forma de discordância das regras impostas. $\mathrm{Na}$ escola particular, as rebeldias ou as indisciplinas também são via de expressão que podem ou não culminar em atos violentos.
Este artigo é parte da dissertação de mestrado "A Concepção de Violência segundo Atores do Cotidiano de uma Escola Particular - uma Análise Psicológica", defendida em abril de 2003, no Departamento de Psicologia Social e do Desenvolvimento, na Universidade Federal do Espírito Santo. A pesquisa contou com o apoio financeiro do CNPq.

10 termo autonomia é usado para designar a moral da autonomia, termo usado por Piaget no estudo do desenvolvimento moral na criança. A moral da autonomia tem como característica principal a capacidade de reconhecer o ponto de vista alheio e também de defender seu próprio posicionamento frente às diversas situações da vida. As regras são consideradas provisórias, uma vez que a noção de análise $e$ propostas coletivas estão presentes. 
As respostas mais freqüentes foram: autoritarismo, agressão física e verbal entre professor e aluno, briga entre alunos e drogas.

2 A escola pesquisada sera sempre mencionada dessa forma.
O objetivo desta pesquisa foi verificar as concepções da equipe pedagógica, dos auxiliares de disciplina e de um grupo de estudantes de uma escola particular a respeito do tema violência na escola e suas causas e analisar como esses atores lidam com a violência nesse espaço.

A abordagem teórico-metodológica que norteia a pesquisa foi baseada nos estudos de Jean Piaget a respeito do desenvolvimento da moral na criança e também nos estudos realizados por pesquisadores que trabalham com a visão da Psicologia social.

\section{Aspectos metodológicos}

A pesquisa foi realizada em uma escola particular de ensino fundamental e médio situada na região metropolitana da Grande Vitória (ES). Foram entrevistados quatro estudantes, quatro professores, duas pedagogas, dois auxiliares de disciplina e o diretor da escola. Os sujeitos eram dois estudantes do sexo masculino (um cursando a oitava série do ensino fundamental e o outro, o segundo ano do ensino médio) e dois, do sexo feminino (uma cursando a sétima série do ensino fundamental e a outra, o terceiro ano do ensino médio); dois professores do sexo masculino e dois do feminino, sendo que cada um deles ministrava aulas para as últimas séries do ensino fundamental e para o ensino médio. Todos os sujeitos da pesquisa faziam parte da dinâmica da escola por, pelo menos, três anos.

Essas séries escolares foram escolhidas pelo fato de os estudantes que as cursavam estarem na faixa etária de 13 a 18 anos. Conforme Piaget (1994), é a partir dos 12 anos, aproximadamente, que um indivíduo começa a construir moral autônoma, podendo então refletir, de maneira mais crítica, sobre temas semelhantes ao desta pesquisa.

Os professores dessas séries fizeram parte do estudo porque lidavam justamente com alunos que tinham mais de 12 anos, ou seja, com adolescentes. Esse período caracteriza-se pela formação do pensamento crítico e dos questionamentos sobre a realidade que os cerca, portanto, podem surgir conflitos na escola, uma vez que as regras possivelmente serão questionadas.

A coleta de dados, nesta pesquisa, realizou-se por meio de entrevistas semi-estruturadas, realizadas individualmente.

O método utilizado para analisar as entrevistas foi a "análise de conteúdo", tendo como base a autora Bardin (1977).

\section{Resultados}

Os temas principais foram agrupados em oito categorias de análise. Neste artigo, discutiremos apenas três categorias, denominadas: 1) o que é violência na escola?; 2) violência na escola $X$; 3) causas da violência. Mais adiante, discutiremos também como os atores escolares lidam com a violência.

\section{O que é violência na escola}

As respostas mais freqüentes foram: autoritarismo, agressão física e verbal entre professor e aluno, briga entre alunos e drogas.

No total das dezesseis respostas dadas, dez indicam um tipo de violência em nível verbal e psicológico (humilhação, coação, discussões, desrespeito ao próximo). As outras seis respostas focam o aspecto da agressão física (porte de armas, drogas, agressão física, briga de gangues, depredação). Dos treze entrevistados, três falaram apenas sobre a agressão física como violência na escola.

Muitos citaram a temática da falta de respeito, afirmando que isso pode ocasionar revolta, levando, assim, a atitudes violentas. O próprio ato de "faltar com o respeito a alguém" também é visto como um tipo de violência.

Debarbieux (2001), fazendo um levantamento das pesquisas sobre violência nas escolas 
francesas, afirma que essas pesquisas têm revelado a presença cada vez maior da violência verbal ou da "falta de respeito" nas relações entre os participantes da dinâmica escolar. As principais queixas de alunos e professores franceses enfocam mais a "falta de respeito", as incivilidades, do que agressões físicas.

Segundo Abramovay e Rua (2002), "as incivilidades contra pessoas podem tomar a forma de intimidações físicas (empurrões, escarros) e verbais (injúrias, xingamentos e ameaças)" (p. 74).

As incivilidades são os embates cotidianos, as divergências por vezes não discutidas e não negociadas que se expressam em forma de "agressões menores", pois vêm com uma roupagem que choca menos que uma agressão física, por exemplo. São essas "agressões menores" que acabam minando o clima do ambiente escolar. "A incivilidade permite pensar as microviolências que, se acumulando, tornam inabitável o mundo dos homens" (Debarbieux, 2001, p. 179).

Pensando a realidade brasileira, nota-se que as estatísticas geralmente retratam a condição da escola pública realçando muito mais as violências físicas ou contra o patrimônio da escola do que as violências que se estabelecem quotidianamente nas relações interpessoais. Embora haja um discurso pedagógico do que é a violência, abordando todos os aspectos envolvidos, formando, assim, uma classe de discurso "politicamente correto", percebe-se uma fraca discussão entre professores, pedagogos e diretoria dos casos de violências que efetivamente estão presentes na escola. Por vezes, como cita Abramovay e Rua (2002), as agressões verbais são consideradas precursoras de ocorrências graves, como, por exemplo, as agressões físicas, e não como práticas violentas em si mesmas.

Como se pode perceber, a violência na escola $X$ é sentida não somente como agressão física mas também como formas de relação estabelecidas no cotidiano escolar. No entanto, esse discurso oscila quando os entrevistados falam sobre as causas da violência e contam experiências pessoais vivenciadas no magistério. Embora haja o reconhecimento que a violência na escola possa ocorrer nas relações entre professores e alunos, as causas mais citadas para essa problemática foram relacionadas ao contexto familiar e social e pouco direcionadas para as práticas pedagógicas. É possível observar também os diferentes pesos dados às diversas formas de violência e até mesmo a mudança de postura quando se passa a falar da escola pesquisada.

\section{Violência na escola X}

A primeira reação de quase metade dos entrevistados quando perguntados se, do seu ponto de vista, havia violência na escola $X$, foi de negar a existência dessa problemática na escola. Alguns ficaram até mesmo surpresos com a realização de uma pesquisa sobre violência na escola $X$, uma vez que ela é vista por eles como um espaço muito tranqüilo. Porém, no decorrer da entrevista, esses respondentes foram refletindo com mais cuidado sobre as diversas situações que vivenciam no cotidiano escolar. Também começaram a contar casos de agressões verbais que, antes, na definição do que é violência, tinham considerado como tal.

Mais da metade dos respondentes disse que a violência mais presente na escola Xé a agressão verbal.

As drogas aparecem na resposta de três entrevistados. Praticamente todos os respondentes afirmam que é possível encontrar alunos usando drogas em escola particular, porém, somente três afirmaram que já houve alunos da escola X envolvidos com drogas.

Essa postura de parte dos entrevistados em negar a incidência de violência e drogas no grupo a que pertencem, ou seja, em não aceitar que "o meu grupo" possa ser palco de problemas complexos, foi também notado por Joffe (1994) em seu estudo sobre as representações sociais da Aids em jovens sul-africanos e britânicos.
Mais da metade dos respondentes disse que a violência mais presente na escola $X$ é a agressão verbal. 
A autora observou que tanto os jovens sulafricanos quanto os britânicos apontavam o continente do outro como o originário da Aids. "As pessoas dizem 'eu não', 'não o meu grupo' quando falam sobre a origem e a disseminação da Aids" (Joffe, 1994, pp. 300-301).

Joffe (1994) afirma que a tendência é de projetarmos sobre o "outro" as questões que nos ameaçam ou que nos são incertas. Essa forma de lidar com o desconhecido (ou com algo que ainda nos aterroriza) talvez ocorra porque, além de não o conhecermos bem, ainda não temos ferramentas eficazes para lidarmos com ele.

Na escola $X$, é possível observar essa atitude do "eu não", "o meu grupo não" quando a questão em tela é a violência e, principalmente, as drogas. Das oito categorias descritas, o tema drogas aparece, em diferentes proporções, em cinco delas. A maioria dos informantes que, em algum momento, falaram sobre drogas, se referiam à presença delas em outras escolas particulares e nas escolas públicas. Não somente com relação às drogas, mas a todo tipo de violência, a imagem que os entrevistados têm é que a escola pública abriga todas as problemáticas possíveis, enquanto a escola privada também teria ocorrências de violência, embora com menor incidência.

Ao apontar as mazelas do ensino público e o modo de vida de sua clientela, insinuando que a violência reside nesses espaços, as classes média e alta, e, em conseqüência, a escola particular, "fazem de suas próprias práticas um conjunto de práticas 'puras'“ (Joffe, 1994, p. 319). Isso pode contribuir para o sentimento, nos integrantes da escola particular, de que, nesse espaço, eles estão imunes à violência, pelo menos em se tratando de sua forma mais evidente, a saber, a violência física e as drogas. As práticas educativas e o modo de relacionamento interpessoal dentro da escola particular podem ser vistas como formas "saudáveis" de vivenciar a escola, acrescentando-se a isso o tipo de clientela que possui, criando, assim, todo um conjunto de características "inibidoras" da violência. Com isso, a necessidade de falar sobre essas problemáticas pode sucumbir, uma vez que a escola acredita na eficiência de suas práticas na prevenção da violência.

Na escola $X$, poucos casos de violência foram citados. Não se trata de negar essas informações acreditando que a escola "esconda" os casos ocorridos em seu espaço. A questão colocada aqui se refere a uma negação da possibilidade e da própria ocorrência de violência (física, verbal, psicológica) na escola e não à quantidade de casos. Seja qual for o grau de incidência de violência, a questão é se a escola está atenta a ela e se a discute, ao invés de adotar uma postura de "não falar sobre" ou de desconsiderar sua relevância, já que, em outras escolas, os índices de violência são maiores.

Outro importante ponto citado pelos entrevistados diz respeito às pequenas agressões entre os adolescentes nas aulas de educação física, brincadeiras que são consentidas pelas partes envolvidas e exaltações verbais quando estão nervosos. Esses comportamentos foram citados não como violentos, mas como algo natural da adolescência. Dois entrevistados acham, inclusive, que é normal o adolescente ser agressivo. Essa naturalização da agressividade na adolescência foi encontrada também na pesquisa de Guimarães (1996), na qual os professores entrevistados afirmaram que "a escola não era violenta, pois as brigas, os roubos e os xingamentos eram 'coisas deles' [alunos], 'natural da idade'” (p. 147).

Esse estereótipo da adolescência, segundo Oliveira e Costa (1997), remonta a certos estudos psicológicos de teóricos como Anna Freud, Stanley Hall e Harry Sullivan, que vêem a adolescência como uma fase, em geral, conflituosa. Oliveira e Costa (1997) realizaram uma pesquisa com 221 adolescentes mineiros, buscando saber quais eram suas maiores preocupações no dia a dia. Verificaram que os adolescentes da amostra não apresentavam dilemas e preocupações extremamente complexos que pudessem justificar e respaldar o estereótipo popular que diz ser a adolescência 
uma fase de rebeldia e de muitos conflitos. $\mathrm{Na}$ análise dos dados dessa pesquisa, destacou-se a categoria que contempla os temas estudo e trabalho, ou seja, esses dois temas foram as preocupações mais recorrentes nos adolescentes da amostra. A questão da busca da independência, da autonomia e o questionamento da autoridade dos pais também foram citados pelos adolescentes como passos importantes para suas vidas. A terceira categoria de resposta mais citada foi em relação aos conflitos vivenciados nas relações familiares, o que, de certa forma, desmonta a idéia de que o adolescente perde os vínculos afetivos com a família nessa fase do desenvolvimento. Para esses adolescentes, a família continua sendo importante em suas vidas, porém isso não os impede de buscar sua autonomia e de expor seus pontos de vista. Os conflitos que emergem na família são sentidos e refletidos pelos adolescentes, contrariando a concepção que prega uma certa indiferença de sua parte quanto aos problemas familiares, alegando egoísmo nessa fase.

Tendo em vista os resultados da pesquisa de Oliveira e Costa (1997), pode-se dizer que a adolescência não representa, necessariamente, uma fase de revolta, conflitos e agressividade. Há dilemas, dúvidas e insegurança quanto às escolhas que o adolescente deverá fazer (como a escolha de uma profissão), mas essas angústias não são tão dramáticas a ponto de definir ou rotular comportamentos na adolescência.

O autoritarismo ${ }^{3}$ também foi citado nas entrevistas como um tipo de violência presente na escola $X$. Todavia, somente dois entrevistados assumiram que, na escola X, há, em certos momentos, posturas autoritárias. Novamente, nesse momento, o discurso "politicamente correto" tropeça. A principal violência apontada é a verbal, porém não fica claro se, dentre esse tipo de violência, está o autoritarismo do professor ou da escola sobre o aluno.

Embora o tema autoritarismo apareça algumas vezes ao longo das entrevistas, ele destaca-se muito pouco quando se fala de violência na escola X. Por mais que se discuta a necessidade de amenizar o autoritarismo na escola e até mesmo a classificação dessa postura como violência, no momento exato em que se fala de modos de violência, o autoritarismo é esquecido ou não é citado abertamente, sobressaindo, assim, as repostas que apontam atitudes nitidamente violentas.

\section{Causas da violência na escola}

A maioria dos entrevistados (nove dos treze) aponta a "família desestruturada" ${ }^{4}$ como a principal causa de violência na escola. As dificuldades no convívio familiar são percebidas como possíveis desencadeadoras de violência nos alunos. A escola seria apenas o lugar onde esses conflitos internalizados pelos alunos eclodiriam.

O destaque da família como espaço com maior propensão a desencadear atos violentos nas crianças e adolescentes e também o fracasso escolar são percebidos em várias pesquisas (Abramovay e Rua (2002), Guedes (1999), Minayo et al (1999), entre outras).

Na pesquisa de Minayo et al (1999), verifica-se que os educadores entrevistados de escolas particulares "mencionam que os pais não comparecem [à escola] alegando não terem tempo e tentam resolver o problema por telefone, inviabilizando, assim, uma solução conjunta" (p. 122).

Os entrevistados da escola X também reclamam da falta de tempo dos pais para irem à escola conversar a respeito do filho. Todavia, a maioria dos entrevistados considera boa a relação com os pais; segundo aqueles, a maioria dos pais coopera com a escola, mas, mesmo contando com essa cooperação, os entrevistados dizem que os pais não têm se dedicado suficientemente aos filhos. Apontam, inclusive, a entrada da mulher no mercado de trabalho como fato que ajudou a acentuar esse distanciamento entre pais e filhos. Estes ficam
30 termo autoritarismo e usado pelos entrevistados em várias ocasiōes. Esse termo, segundo os pesquisados, refere-se a uma postura inflexivel do professor, em que este oferece pouca ou nenhuma oportunidade para que os alunos expressem suas opiniōes e desejos.

4 Respeitando o trabalho original da dissertação de mestrado, o termo está entre aspas, designando o que, na fala dos sujeitos, engloba: a separação do casal; falta de disponibilidade para diálogo com os filhos alcoolismo dos pais; mãe omissa; pais que não corrigem os erros dos filhos; violência doméstica: ausência dos pais aliada à necessidade de trabalhar e falta de limite para os filhos. Portanto, não se trata, aqui, da concepção científica mesma do termo, a qual pode ser encontrada na literatura científica. 
[...] os educadores evidenciam em últimos lugares o próprio despreparo para o exercício da profissão e a má administração do sistema escolar como motivos para o mau rendimento dos alunos, demonstrando uma visão, no mínimo, pouco crítica sobre si mesmos e suas próxis Minayo cada vez mais tempo sozinhos em casa e conversam menos com os pais. A escola, portanto, sente-se sobrecarregada na sua missão de educar, uma vez que a família não tem contribuído de forma satisfatória para o desenvolvimento moral e intelectual dos filhos. Diante dessa situação, a escola muitas vezes sente-se solitária na realização de seu trabalho. A busca de parceria com a família é a estratégia mais utilizada; contudo, ela tem encontrado muitos obstáculos e nem sempre essa cooperação se torna possível.

Na escola $X$, há reuniões com os pais regularmente. A escola divide o ano letivo em quatro bimestres. No primeiro bimestre, há uma reunião para recepcionar os pais e esclarecer algumas regras da escola e a forma como ela funciona. Todo fim de bimestre há uma reunião para os pais junto aos professores. Nessas reuniões, os pais conversam com os professores -exclusivamente sobre seu filho. No decorrer dos bimestres, há reuniões extras com os pais que têm filhos com maior dificuldade na escola. Todas essas reuniões, exceto a de recepção, ocorrem separadamente das dos outros pais, ou seja, não há um momento em que os pais possam, juntos, conversar e compartilhar suas dificuldades. $\mathrm{Na}$ realidade, é feito um atendimento individual pelo professor, caracterizando, assim, um trabalho bastante segmentado que reforça ainda mais um não compromisso dos pais com a escola; seu compromisso é apenas falar do filho, e não de uma comunidade escolar. Torna-se difícil, então, ter uma noção mais geral do trabalho pedagógico desenvolvido na escola e das problemáticas que esta enfrenta. Cada problema vivido não é compartilhado com alguém que não esteja envolvido diretamente no dilema. A escola X, paradoxalmente, ao mesmo tempo em que reivindica um trabalho conjunto com a família, não fornece suporte para que os pais se sintam comprometidos com suas vitórias e fracassos; reforça-se uma postura individualista, de não compromisso com o coletivo. Dessa forma, os pais se sentem responsáveis apenas pelo desenvolvimento do filho (como se isso fosse possível sem relevar a comunidade escolar) e não agem como participantes na construção de novas normas e estratégias para o aperfeiçoamento do ambiente escolar.

Minayo et al (1999) verificam que os principais motivos para o mau rendimento escolar dos alunos, conforme indicado por professores da rede pública e privada, são: falhas do aluno e de sua família; conteúdos escolares que não apresentam relação com a realidade de vida dos alunos; diferenças culturais e ambiente em que vivem os jovens.

[...] os educadores evidenciam em últimos lugares o próprio despreparo para o exercício da profissão e a má administração do sistema escolar como motivos para o mau rendimento dos alunos, demonstrando uma visão, no mínimo, pouco crítica sobre si mesmos e suas práxis (Minayo et al, 1999, p. 125).

A escola, ao mesmo tempo em que apresenta um discurso em direção à busca de um trabalho conjunto com os pais, culpabiliza-os pelas dificuldades que os filhos apresentam na escola. No mesmo instante em que cobra maior interesse pela vida acadêmica do filho, não abre espaço para reuniões em que efetivamente se discutam as práticas escolares, o processo de aprendizagem, as normas da instituição, os problemas emergentes e as possíveis formas de resolução dos impasses. Com isso, os pais não se sentem participantes da dinâmica escolar, uma vez que não são convidados a pensar sobre o funcionamento da escola. A escola não demonstra que precisa dos pais para realizar suas tarefas, passando uma imagem de autosuficiência. Talvez essa postura da escola seja importante para se entender o porquê de alguns pais não atenderem ao chamado da escola para resolver algum conflito com o filho. Isso pode tornar-se ainda mais evidente quando a escola é particular, pois, além dessa idéia de autosuficiência da escola, ainda há a questão do pagamento por um serviço, que muitas vezes é entendido como se a escola estivesse sendo paga para, sozinha, resolver todos os problemas. 
A segunda resposta com maior freqüência na escola $X$ diz respeito ao ambiente em que o aluno ou a escola está inserido. Se o aluno residir em um ambiente violento (que, diga-se de passagem, quase sempre se torna sinônimo de lugar empobrecido), as atitudes violentas que porventura vier a apresentar estarão relacionadas a esse ambiente violento no qual cresceu. Quando é a escola que está situada em uma região violenta, os atos de vandalismo contra ela são "justificados" pelo local em que ela está inserida e pela qualidade de sua clientela.

Na pesquisa de Abramovay e Rua (2002), foram encontradas escolas consideradas seguras em lugares com alto índice de violência e, viceversa, escolas tidas como violentas inseridas em locais vistos como seguros, ou seja, a questão da violência na escola não pode ser ligada tão diretamente ao grau de segurança do local onde a escola está situada e nem às boas qualidades das pessoas que a freqüentam (pessoas idôneas, que respeitam ao próximo, provenientes de famílias estruturadas, etc.). As autoras apontam a construção de um sentimento de pertencimento e de participação da dinâmica escolar como ponto-chave para construção da paz nesse espaço.

Baker (1998) também ressalta a necessidade dos alunos em se sentirem participantes de uma comunidade escolar. Segundo esse autor, para que se possa entender um pouco melhor a violência na escola, é preciso considerar o contexto escolar, ou seja, a sua realidade, e verificar se a escola fornece condições para que o aluno se sinta a ela integrado. A violência na escola pode representar a ausência de um sentimento de identidade e de pertencimento do aluno. Este, por estar excluído da comunidade escolar, não participa da formulação de regras e, por isso mesmo, não entende o contrato social ali formado, não se sentindo, dessa forma, com o compromisso de respeitálo.

Para Baker (1998), pertencer à comunidade escolar significa atuar em uma relação entre indivíduos que constroem valores e idéias na busca de um objetivo comum. Significa desenvolver uma cooperação entre os atores escolares visando à construção de regras que beneficiem um coletivo e permitam que o processo de aprendizagem se efetue.

Baker (1998) cita alguns estudos que enfatizam a história da afetividade pessoal de alunos como um importante indicador de como se comportarão no espaço escolar. Contudo, seu enfoque está em como a escola lida com esse aluno que, por vezes, não apresenta habilidade para negociar em um impasse. Aliás, o autor também coloca a dificuldade da escola em detectar as necessidades do aluno e a de ela mesma propiciar espaço para negociação.

A escola pode produzir violência quando falha em sua tarefa de "fornecer para os alunos um contexto social significativo. Se o ambiente da escola é percebido como hostil e ameaçador, os alunos podem responder com uma série de comportamentos violentos" (Baker, 1998, p. 36).

Quanto ao autoritarismo, é interessante destacar que os professores, os auxiliares de disciplina e a equipe pedagógica da escola $X$ vêem essa postura como nociva ao espaço escolar, devendo ser evitada. Todavia, poucos foram os que a colocaram como o primeiro fator quando se pensa em violência na escola, ou seja, poucos refletiram primeiramente as suas práticas e as da escola para depois pensar na realidade de cada aluno.

Quando se fala de autoritarismo, lembramonos da questão da formação da moral autônoma na criança, assunto esse muito discutido por Piaget (1994), La Taille (1996) e Araújo (1996). Este último realizou uma pesquisa em escolas e constatou que a escola que desenvolvia um ambiente de cooperação entre os alunos e era menos autoritária contribuía para que os alunos alcançassem a moral autônoma mais rapidamente, tornando-se crianças mais críticas e menos individualistas. Para Araújo (1996),

A autonomia moral pressupõe essa capacidade racional de o sujeito compreender as 
contradições em seu pensamento, em poder comparar suas idéias e valores aos das outras pessoas, estabelecendo critérios de justiça e igualdade que muitas vezes o levarão a contrapor-se à autoridade e às tradições da sociedade para decidir entre o certo e o errado (Araújo, 1996, p. 110).

O autoritarismo pode prejudicar o desenvolvimento da autonomia do aluno, constituindo-se, assim, como um tipo de violência, pois, além de frear a criatividade do aluno, essa postura subestima sua própria capacidade de reflexão e crítica, fundamentais para o desenvolvimento moral.

Percebe-se que a maioria das respostas na escola $X$ direciona as causas da violência para fatores externos a ela. Das quinze respostas apresentadas como causas da violência na escola, apenas quatro estão diretamente vinculadas às relações tecidas na escola e às dificuldades concernentes aos recursos humanos, materiais e formação profissional. A freqüência dessa classe de respostas é sete, contra vinte e oito das outras respostas que indicam aspectos externos à escola.

\section{Como os atores escolares lidam com a violência}

O diálogo ${ }^{5}$ como um meio de solucionar os impasses ou lidar com algum tipo de violência foi destacado na maioria das entrevistas.

É interessante observar que, embora o diálogo e o trabalho em equipe sejam lembrados nas entrevistas na escola $X$, a resolução dos problemas enfrentados na sala de aula fica restrita ao professor e ao aluno e, quando muito, à coordenação e orientação, sendo, em último caso, encaminhada à diretoria. Um problema que porventura tenha acontecido com um professor e um aluno em sala de aula é discutido e conversado entre eles. Mesmo que a orientação e coordenação se reunam com o professor e o aluno para buscarem resolver um certo conflito, essa ação, ainda assim, pode ser considerada individual. Os problemas são discutidos e resolvidos apenas com os envolvidos; parece não haver um espaço para a troca de experiências e a discussão dos problemas enfrentados pelo professor. O trabalho, então, é solitário. Cada um com seu problema, tentando resolvê-lo como consegue. Não há a preocupação de estar se formando um grupo de professores para dialogarem, para pedirem opinião aos outros colegas sobre suas práticas, para pedir ajuda e ter um feedback das atitudes e posturas adotadas em sala de aula. Os grupos constituídos buscam apenas discutir o planejamento das aulas, questões relacionadas às programações e eventos da escola.

É importante a escola promover um espaço para que os professores e demais profissionais que lá atuam possam dialogar, trocar experiências e desenvolver novos métodos de ensino e de enfrentamento das dificuldades vividas em sala. Questões como a violência na escola são complexas demais para serem pensadas e trabalhadas isoladamente. Percebemos que, na escola pesquisada, os problemas concernentes a atos violentos são tratados somente com os envolvidos. Não são discutidos com os demais professores, embora muitos enfrentem esses mesmos problemas em suas aulas.

Pensando, neste momento, a respeito do diálogo como ferramenta para negociar conflitos com os alunos, é possível fazer um questionamento muito pertinente: no contexto educacional, podemos afirmar que o diálogo é sempre possível? Ou será que há situações em que efetivamente não há chance de manter um diálogo na tentativa de se fazer entender e de também entender outrem?

Acreditamos que, para que o diálogo seja ferramenta possível, é preciso que haja um respeito mútuo mínimo que permita às partes falarem e se ouvirem, um respeito que proporcione boa vontade, no sentido de não desqualificar o outro antes mesmo de ouvir e interpelar seus argumentos.

Nos Parâmetros Curriculares Nacionais, o diálogo é visto como ferramenta imprescindível para a 
construção da democracia em sala de aula e pressupõe um grau mínimo de autonomia para sua efetivação, uma vez que, sem ela, tornase difícil a comparação entre os diferentes pontos de vista.

De fato, para viver em democracia, é necessário explicitar e, se possível, resolver conflitos por meio da palavra, da comunicação, do diálogo. Significa trocar argumentos, negociar. Ora, para que o diálogo seja profícuo, para que possa gerar resultados, a racionalidade é uma das condições necessárias. Os interlocutores precisam expressar-se com clareza - o que pressupõe a clareza de suas próprias convicções - e serem capazes de entender os diferentes pontos de vista. (Parâmetros Curriculares Nacionais - Ética, p. 71)

Na escola, é possível vivenciar situações em que o respeito mútuo, a cooperação e a autonomia ainda não foram desenvolvidos de forma que permitam resolver os impasses e construir regras coletivamente. Nesse ponto, lanço uma questão: se a autonomia ainda não está desenvolvida a ponto de podermos trabalhar somente por meio do diálogo, devemos, então, recorrer à coação, a uma postura mais rígida para que um mínimo de ordem necessária ao aprendizado se estabeleça?

Essa questão é assaz complexa, uma vez que, no decorrer deste trabalho, foi enfatizada a necessidade de se reduzir o autoritarismo e a coação para que a moral da autonomia se desenvolvesse. Parece, então, que estamos diante de um paradoxo: como diminuir a coação se o diálogo também não é possível? Mas, por outro lado, será possível abandonar totalmente e de uma só vez uma postura (coação, autoritarismo) para adotarmos imediatamente outra? Pensemos na educação familiar de crianças bem pequenas, de dois a cinco anos de idade. Nessa fase, é impossível para os pais educar essas crianças apenas utilizando-se do diálogo. O que ocorre, na maioria das vezes, é que os pais recorrem tanto à coação quanto ao diálogo, e que, conforme a criança vai crescendo, o diálogo toma cada vez mais espaço e a coação tende a tornar-se mais escassa. Pode-se dizer, então, que o diálogo é privilegiado na relação entre pais e filhos, embora a coação não tenha sido definitivamente eliminada.

Na escola, quando o diálogo não é possível, muitas vezes temos que agir com autoritarismo por um certo tempo, em algumas situações, até que um respeito mínimo seja construído. Dessa forma, subtende-se que ora o diálogo é utilizado, ora o autoritarismo. O importante é que o diálogo seja sempre buscado como a primeira opção na manutenção das relações escolares. Não sendo ele possível, a autoridade do professor, que pode ser confundida, nesse momento, com autoritarismo, entra em ação. Todavia, é bom que sempre fique claro para os alunos que eles podem trabalhar juntos na elaboração das regras da sala de aula; essa hipótese não é descartada, porém, para que isso seja viável, eles precisam cooperar entre si, respeitando a opinião uns dos outros.

“O respeito ganha seu significado mais amplo quando se realiza como respeito mútuo: ao dever de respeitar o outro, articula-se o direito, a exigência de ser respeitado" (Parâmetros Curriculares Nacionais, 2003, p. 96). É necessário que essa relação de direito e dever, que é uma relação de reciprocidade, esteja bem clara para os alunos.

Quando, em uma sala de aula, não há respeito algum entre os alunos e entre professor e alunos, onde ninguém consegue se ouvir e se fazer ouvir, a moral da autonomia também terá dificuldade em se desenvolver. Portanto, é preciso que haja uma intervenção do professor. Não há como deixar "tudo ocorrer espontaneamente", pois isso implicaria caos total. A idéia de não interferir nesse processo destrutivo em sala devido à "proibição construtivista" de coagir e ser autoritário leva a um empobrecimento no processo de aprendizagem, e o lugar de autoridade do professor (que não é descartado pelo construtivismo) fica vago.
Na escola, é possivel vivenciar situações em que o respeito mútuo, a cooperação e a autonomia ainda não foram desenvolvidos de forma que permitam resolver os impassese construir regras coletivamente. 
Enfim, o diálogo é uma questão muito complexa, porque existe o outro lado da moeda: quando ele não é possível. Creio que as atitudes do professor devem sinalizar que o diálogo é o caminho desejável, e as práticas na sala de aula devem buscar construir o ambiente necessário para que o diálogo seja, de fato, uma realidade.

\section{Conclusão}

Estudar a concepção de violência dos atores escolares é importante para que se promova modos de enfrentamento da violência no âmbito escolar.

A presença da violência nas escolas públicas e privadas é notada de forma diferenciada. $\mathrm{Na}$ rede pública, os relatos envolvem mais os conflitos físicos, o roubo, as drogas, as ameaças e as brigas entre alunos. Na escola particular, a falta de respeito ao próximo, as agressões verbais e a prepotência dos alunos frente aos professores e funcionários (porque "estão pagando") são as formas de violência mais citadas.

A "família desestruturada" aparece tanto na escola pública quanto na particular; contudo, nesta última, assume mais a característica da falta de tempo dos pais para dialogarem com os filhos devido à grande carga de trabalho. Os entrevistados da escola $X$ disseram que existem famílias com problemas de alcoolismo, porém a maioria citou a questão da ausência do pai e da mãe no dia a dia do filho, muitas vezes tentando-se superar essa ausência ao amenizar as falhas do filho, quando entra em cena uma outra questão, a saber, a do limite.

Nas pesquisas realizadas na rede pública (Lucinda etal, 1999, Guimarães, 1996, Guedes, 1999), a "família desestruturada" aparece com mais casos de alcoolismo, de violência doméstica e até mesmo de despreocupação com a higiene e a aparência do filho. As famílias representadas na escola pública podem ser vistas como dotadas de uma sociabilidade degradante e primitiva quando comparadas às famílias de classe média e alta. Por vezes, essas famílias são consideradas, na rede pública, como nocivas às crianças, acentuando, dessa forma, uma visão estereotipada da "família pobre" e a legitimação do modelo de família burguês. Com isso, a escola responsabiliza a família pelo fracasso escolar ou pelos comportamentos agressivos dos alunos, não percebendo que ela mesma gera o fracasso e a violência quando reproduz as formas de tratamento da família que antes julgou "desapropriadas" e quando subestima a capacidade da criança em aprender e a ser sociável frente a uma outra dinâmica escolar.

A família, portanto, é a primeira a ser lembrada quando se fala em causas da violência, deixando as relações tecidas na escola para segundo (ou último) plano. Nesse momento, é possível refletirmos a respeito da formação profissional. Fazemos essa ligação porque acreditamos que tanto os cursos de graduação quanto os de pósgraduação podem estar falhando na tarefa de trabalhar problemáticas vivenciadas no cotidiano das escolas. Com isso, não instigam o profissional a questionar suas próprias concepções e práticas, favorecendo uma culpabilização da família e do meio onde ela e a escola estão situadas.

Sem disposição para discutir em grupo e estudar sempre as dificuldades na escola, não há como assegurar propostas de prevenção e de enfrentamento eficazes para essas dificuldades. O trabalho precisa ser coletivizado, menos solitário, tornando-se, dessa forma, mais leve e eficaz.

Acreditamos que a diferença entre uma escola violenta e outra não violenta esteja inscrita na forma como as regras são estabelecidas, no sentimento de pertencimento à comunidade escolar e no modo de tratamento dos atores escolares entre si, e não a uma condição direta do tipo de escola - pública ou particular. Uma escola pode ser particular e apresentar um incrível índice de violência, pois não consegue ajudar os alunos a se sentirem parte ativa da escola. Isso independe da classe social dos educandos; a questão de pagar por um serviço 
não é suficiente para que o aluno se sinta um importante ator e autor na dinâmica escolar. Além disso, o pagamento pode também ser entendido de uma forma egoísta: "eu pago, eu mando e posso tudo", e isso não pode ser considerado um sentimento de pertencimento ("eu pertenço à comunidade escolar"), e sim, um sentimento de posse exclusiva ("eu possuo a escola"), descartando os outros atores escolares.
É evidente que a violência não é exclusiva de uma classe social ou de um tipo de escola. Ela é exclusiva de determinadas posturas que anulam, no outro, a possibilidade de diálogo e negociação e fecham as portas para tentativas de diferentes tipos de sociabilização, reproduzindo velhos paradigmas a respeito do que é viver a escola.

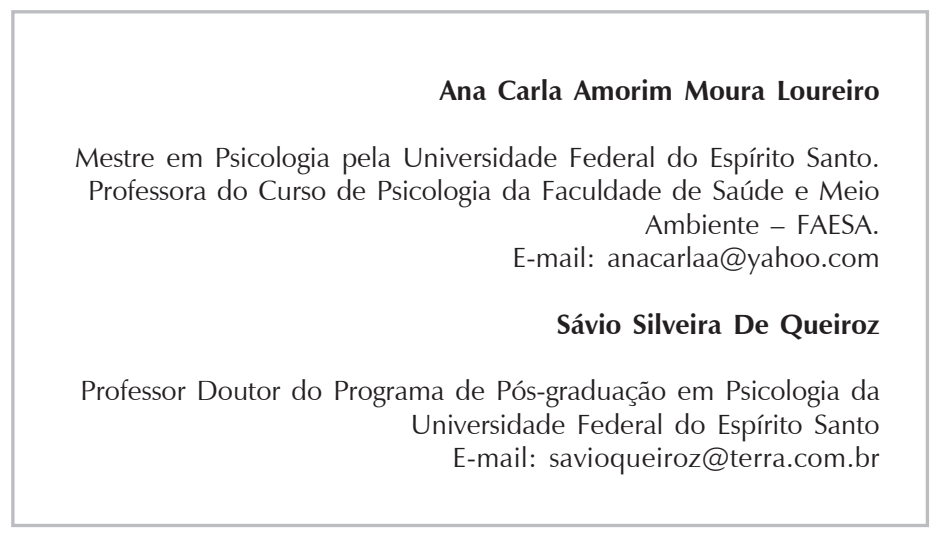

Recebido 13/04/04 Reformulado 13/10/04 Aprovado 28/11/05

ABRAMOVAY, M., RUA, M. das G. Violências nas Escolas. Brasília : UNESCO, Instituto Ayrton Senna, UNAIDS, Banco Mundial, USAID, Fundação Ford, CONSED, UNDIME, 2002.

ARAÚJO, Ulisses Ferreira de. O Ambiente Escolar e o Desenvolvimento do Juízo Moral Infantil. In Macedo, L. de. (org.). Cinco Estudos de Educação Moral. São Paulo: Casa do Psicólogo, 1996, pp. 105-136.

BARDIN, L. Análise de Conteúdo. São Paulo : Edições 70, 1997.

BAKER, J. A. Are we Missing the Forest for the Trees? Considering the Social Context of School Violence. Journal of School Psychology, v. 36, n. 1, Charlottesville, Virgínia, USA,1998, pp. 29-44.

COLOMBIER, C., MANGEL, G., PERDRIAULT, M. A Violência na Escola. Trad. de Roseana Kligerman Murray. São Paulo : Summus, 1989.

DEBARBIEUX, E. A Violência na Escola Francesa: 30 Anos de Construção Social do Objeto (1967-1997). Trad. de Maria de Fátima Simões Francisco. Educação e Pesquisa, v.27, no 1. São Paulo: jan./ jun. 2001, pp. 163-193.

GUEDES, M. G. de S. Violência, Escola e Diálogo. Dissertação de Mestrado em Educação. Programa de Pós-graduação em Educação, Pontifícia Universidade Católica do Rio de Janeiro, 1999.
GUIMARÃES, Á. M. A Dinâmica da Violência Escolar: Conflitos e Referências 